\title{
Sistemas de Informação no Brasil: uma Análise dos Artigos Científicos dos Anos 90
}

\author{
Norberto Hoppen
}

\section{REsUMO}

Este artigo apresenta uma avaliação do estado da arte da área de conhecimento de Sistemas de Informação, no Brasil, a partir da análise de 163 artigos publicados entre janeiro de 1990 e setembro de 1997, em revistas científicas de Administração. Para tanto, analisaram-se os temas abordados nos artigos, as estratégias e as metodologias de pesquisa utilizadas nas pesquisas empíricas, e avaliou-se a qualidade destas pesquisas. Constatou-se que ainda existe forte proporção de ensaios teóricos publicados (41\% no período 1990-7 e 34\% no período 1996-7), que há um predomínio de temas sobre desenvolvimento e uso de Sistemas de Informação no Brasil, que as pesquisas qualitativas (os estudos de caso) e as pesquisas survey são as metodologias utilizadas em $72 \%$ das pesquisas empíricas; a qualidade científica dos artigos ainda é baixa, em razão da não explicitação de como as teorias de base são operacionalizadas, da descrição incompleta dos procedimentos metodológicos e da não validação dos instrumentos de pesquisa.

Palavras-chaves: sistema de informação; pesquisa; avaliação.

\begin{abstract}
An evaluation of the state of the art in the Information Systems domain, in Brazil, is presented in this article. The assessment was obtained by the analysis of 163 articles published between January 1990 and September 1997 in the most important scientific journals in Administration. The analysis was based on the classification of the subjects, developed in the articles, on the research strategies and methodologies adopted in the empirical researches and on the assessment of the scientific quality of the articles. The results showed that (1) there is a strong proportion of theoretical essays published (41\% in the period $1990-7$ and $34 \%$ in the period 1996-7), (2) the most important subjects studied by the authors are development and use of IS in Brazil, (3) qualitative research (cases studies) and survey are the more frequently adopted research methodologies (in $72 \%$ of the empirical studies), and (4) the scientific quality of the articles is low. Because the link between theory and the operationalization of the variables is not elicited, the methodological procedures are incompletely described, and the research instruments are not validated.
\end{abstract}

Key words: information system; research; evaluation. 


\section{INTRODUÇĀO (1)}

A área de Sistemas de Informação (SI) tem-se expandido e evoluído continuamente em razão das mudanças e do impacto econômico que produz nas organizações e na sociedade, e também em função da evolução da própria tecnologia de informação. Para que esta área temática se consolide efetivamente como área de conhecimento, temas específicos devem constituir o objeto de estudo, e o uso de metodologias científicas, normalmente emprestadas de outras disciplinas, devem ter uma aplicação apropriada.

Os estudos já realizados no Brasil, com o propósito de mapear interligações de temas na área de SI, através de uma análise de citação (Silveira Jr. et al., 1996) e analisar estratégias de pesquisa na área, através da análise da adoção do paradigma interpretativo (Rodrigues et al., 1998), não permitem ter uma visão mais ampla e completa da disciplina.

Neste contexto, o presente estudo tem como objetivo avaliar o estado da arte da área de conhecimento de SI, no Brasil, a partir da análise de artigos publicados em revistas científicas (considerando os Anais do ENANPAD como tal) nos anos 90. Para tanto, três elementos de análise são utilizados: o mapeamento dos temas abordados nos artigos, a sistematização das estratégias e das metodologias de pesquisa utilizadas pelos autores nas pesquisas empíricas, e a avaliação da qualidade destas pesquisas, em termos de suas forças e fraquezas. A avaliação dos artigos científicos produzidos no Brasil na área de SI permitirá direcionar mais claramente as estratégias e os temas estudados em pesquisas futuras, contribuindo efetivamente para a consolidação da área de conhecimento.

O texto a seguir, na seção 2, apresenta, sucintamente, o referencial conceitual e o método utilizados na avaliação dos artigos científicos. Na seção 3 são detalhados os resultados obtidos a partir de uma amostra de 163 artigos científicos divulgados entre 1990 e 1997 em 7 publicações. Finalmente, na seção 4, discutem-se os temas abordados com maior freqüência, as metodologias de pesquisa empregadas e a qualidade dos artigos. Tecem-se também comentários sobre as implicações para a consolidação da área de SI como área de conhecimento no Brasil. 


\section{Referencial e Método para a Análise dos Artigos em Sistemas de INFORMAÇĀO}

Nesta seção apresenta-se a definição da amostra estudada, bem como o referencial conceitual e os procedimentos utilizados para a análise dos artigos científicos.

\section{Definição da Amostra}

A amostra é composta por 163 artigos científicos publicados, entre janeiro de 1990 e setembro de 1997, nos seguintes veículos: Anais do ENANPAD (ENANPAD), essencialmente o volume Administração da Informação, Revista de Administração da USP (RA), Revista de Administração de Empresas (RAE), Revista de Administração Pública (RAP), Revista Brasileira de Administração Contemporânea (RBAC), Revista de Administração Contemporânea (RAC) e revista Organizações e Sociedade (O\&S). Estas revistas e anais de congressos foram considerados os veículos mais representativos do que se produz e divulga em termos científicos em SI, como disciplina da área de Administração, no Brasil. A década de 90 foi escolhida por retratar um período já mais consolidado desta área de conhecimento. Todos os artigos da amostra estão referenciados na seção Bibliografia.

Na análise, constatou-se que $41 \%$ dos artigos são ensaios teóricos (vide Quadro 1), isto é, não contêm informações baseadas em estudos empíricos. Por isso os artigos científicos baseados em estudos empíricos são analisados de forma completa: temas abordados, estratégia e metodologia empregadas e qualidade. Para os ensaios teóricos, por sua vez, analisaram-se somente os temas tratados.

\section{Estruturação do Referencial de Mapeamento dos Temas Abordados}

O mapeamento dos temas abordados nos artigos seguiu o esquema de classificação para literatura em pesquisa em SI proposto por Barki et al. (1993). O esquema é baseado em palavras-chaves, compreendendo quatro níveis de detalhamento. Neste estudo utilizou-se o primeiro e segundo níveis de classificação dos temas, os quais estão detalhados no Quadro 1. Este esquema de classificação foi escolhido pela sua abrangência e por ter sido adotado pela revista Management Information Systems Quarterly, uma das principais da área de SI. Para facilitar a classificação, optou-se pela adoção de uma única palavra-chave, a mais significativa, para cada um dos artigos. Dúvidas de sistematização foram dirimidas em duas reuniões de grupo, realizadas com o propósito de obter maior 
consistência nos critérios adotados por cada um dos participantes, aumentando assim a validade deste estudo. Cada artigo foi analisado por uma pessoa; porém, antes de iniciar a análise dos artigos científicos da amostra, cada um dos participantes já havia avaliado mais de 10 artigos em sala de aula em uma espécie de pré-teste.

\section{Quadro 1: Mapeamento dos Temas Abordados nos Artigos em SI ${ }^{(2)}$}

\begin{tabular}{|c|c|c|c|c|c|c|c|c|c|c|c|}
\hline \multirow[t]{2}{*}{$\mathrm{T}_{\text {Temas }}$ Elementos } & \multicolumn{5}{|c|}{$\begin{array}{l}\text { Artigos baseados em } \\
\text { pesquisa empírica }\end{array}$} & \multicolumn{5}{|c|}{ Ensaios teóricos } & \multirow[t]{2}{*}{ Total } \\
\hline & $90 / 1$ & $92 / 3$ & $94 / 5$ & $\begin{array}{l}96 / \\
7\end{array}$ & $\mathbf{S} / \mathbf{T}$ & $90 / 1$ & $92 / 3$ & $94 / 5$ & $\begin{array}{l}96 / \\
7\end{array}$ & $\mathbf{S} / \mathbf{T}$ & \\
\hline A - Disciplinas de Referência & 1 & & 5 & 2 & 8 & 5 & 2 & 4 & 4 & 15 & $\begin{array}{l}23 \\
(14 \%)\end{array}$ \\
\hline AA - Ciências Comportamentais & & & 1 & & 1 & & & & & & 1 \\
\hline AC - Teoria da Decisão & 1 & & 1 & 1 & 3 & 1 & 2 & 3 & 3 & 9 & 12 \\
\hline AD - Teoria da Informação & & & 1 & & 1 & 2 & & 1 & 1 & 4 & 5 \\
\hline AF - Teoria da Administração & & & 2 & 1 & 3 & & & & & & 3 \\
\hline AK - Ciências de Gestão & & & & & & 2 & & & & 2 & 2 \\
\hline B - Ambiente Externo & & & & & & & & 1 & & 1 & $1(1 \%)$ \\
\hline BA - Ambiente Econômico & & & & & & & & 1 & & 1 & 1 \\
\hline C - Tecnologia de Informação & & 1 & & 1 & 2 & & 1 & 1 & & 2 & $4(2 \%)$ \\
\hline CA - Sistemas Computacionais & & 1 & & 1 & 2 & & 1 & 1 & & 2 & 4 \\
\hline D - Ambiente Organizacional & 2 & 2 & 1 & 2 & 7 & 1 & & & & 1 & $8(5 \%)$ \\
\hline DA - Características Organizacionais & 2 & 2 & & 2 & 6 & 1 & & & & 1 & 7 \\
\hline DD - Dinâmica Organizacional & & & 1 & & 1 & & & & & & 1 \\
\hline E - Administração de SI & 2 & 4 & 12 & 8 & 26 & 4 & 1 & 2 & 1 & 8 & $\begin{array}{l}34 \\
(21 \%)\end{array}$ \\
\hline EA - Administração de Dados & 1 & & & 1 & 2 & & & & & & 2 \\
\hline EF - Planejamento de SI & & 1 & 2 & 1 & 4 & 2 & & & 1 & 3 & 7 \\
\hline EG - Organização de SI & 1 & & 4 & & 5 & 1 & & 1 & & 2 & 7 \\
\hline EI - Avaliação de SI & & 2 & 5 & & 7 & 1 & 1 & 1 & & 3 & 10 \\
\hline EJ - Controle de SI & & 1 & & & 1 & & & & & & 1 \\
\hline EL - Implicações Gerenciais de SI & & & 1 & 6 & 7 & & & & & & 7 \\
\hline $\begin{array}{l}\text { F - Desenvolvimento e Operacão de } \\
\text { SI }\end{array}$ & 2 & 1 & 2 & 3 & 8 & 4 & 4 & & & 8 & $\begin{array}{l}16 \\
(10 \%)\end{array}$ \\
\hline FA - Estratégias de Desenvolvim. de SI & & & & 3 & 3 & 3 & 2 & & & 5 & 8 \\
\hline FB - Atividades do Ciclo de Vida de SI & & & 1 & & 1 & & 1 & & & 1 & 2 \\
\hline $\begin{array}{l}\text { FC - Métodos e Ferramentas de } \\
\text { Desenvolvimento de SI }\end{array}$ & 1 & 1 & & & 2 & 1 & 1 & & & 2 & 4 \\
\hline FD - Implementação de SI & 1 & & 1 & & 2 & & & & & & 2 \\
\hline G - Uso de SI & 3 & 8 & 4 & 5 & 20 & 2 & 3 & 2 & 1 & 8 & $\begin{array}{l}28 \\
(17 \%)\end{array}$ \\
\hline GA - Uso Organizacional de SI & 2 & 5 & 2 & 4 & 13 & 2 & 1 & 2 & 1 & 6 & 19 \\
\hline GB - Usuários & 1 & & & & 1 & & 1 & & & 1 & 2 \\
\hline GC - Tipo de Suporte de SI & & 3 & 2 & 1 & 6 & & 1 & & & 1 & 7 \\
\hline H - Sistemas de Informação & 2 & 8 & 4 & 7 & 21 & 2 & 2 & 6 & 5 & 15 & $\begin{array}{l}36 \\
(23 \%)\end{array}$ \\
\hline HA - Tipos de SI & & 2 & 3 & & 5 & 2 & 2 & & 4 & 8 & 13 \\
\hline HB - Áreas de Aplicação de SI & 2 & 6 & & 7 & 15 & & & 6 & 1 & 7 & 22 \\
\hline HD - Características de SI & & & 1 & & 1 & & & & & & 1 \\
\hline I - Educacão e Pesquisa em SI & & & 3 & 1 & 4 & 1 & 1 & 2 & 4 & 8 & $12(7 \%)$ \\
\hline IA - Educação em SI & & & & 1 & 1 & & 1 & & 1 & 2 & 3 \\
\hline IB - Pesquisa em SI & & & 3 & & 3 & 1 & & 2 & 4 & \begin{tabular}{|l|l|}
7 \\
\end{tabular} & 10 \\
\hline Total Geral & 12 & 24 & 31 & 29 & \begin{tabular}{|l|l}
96 \\
$(59 \%)$
\end{tabular} & 19 & 14 & 18 & 16 & \begin{tabular}{|l|l|}
$\begin{array}{l}67 \\
(41 \%)\end{array}$ \\
\end{tabular} & 163 \\
\hline
\end{tabular}




\section{Estruturaçăo do Referencial para a Análise das Metodologias e Estratégias de Pesquisa}

Para a análise das estratégias e metodologias de pesquisa utilizou-se o guia de avaliação de artigos de pesquisa proposto por Hoppen et al. (1997). Os elementos adotados neste estudo estão detalhados no Quadro 2 e devem permitir a análise da adequação entre a natureza do estudo (exploratória, descritiva ou explanatória) e a metodologia empregada (pesquisa survey, experimental e qualitativa; esta última envolve estudo de caso, pesquisa-ação e outros). O desenvolvimento de SI em organizações foi classificado como pesquisa-ação, pois envolve mudanças organizacionais. Como outros métodos de pesquisa classificou-se a observação participante e o desenvolvimento de SI em laboratório (testes de simulação, etc).

\section{Referencial para a Análise da Qualidade dos Artigos Científicos}

A qualidade científica de uma pesquisa e do artigo que a divulga resulta, fundamentalmente, da sua validade externa (o poder de generalizar os resultados) e da sua validade interna (se efetivamente está sendo medido o que se deseja mensurar). Características que permitem avaliar estas validades e, por conseqüência, a qualidade dos estudos são: a pertinência do assunto tratado, as teorias e conceitos de base, o rigor metodológico adotado, a coleta e análise dos dados e a profundidade dos resultados obtidos. Para a avaliação de artigos científicos, Hoppen et al. (1997) detalharam os citados elementos estratégia de pesquisa, questão de pesquisa, desenho de pesquisa, instrumentos de medida e coleta de dados, validade do construto, análise dos dados, apresentação dos resultados e estilo do artigo. No presente estudo, os conjuntos de critérios acima descritos foram sintetizados com o propósito de facilitar a análise comparativa de pesquisas, utilizando métodos distintos. Os critérios resultantes estão detalhados no Quadro 3 (pesquisa survey), Quadro 4 (pesquisa experimental) e Quadro 5 (pesquisas qualitativas), apresentados na seqüência.

\section{Os Resultados Obtidos}

\section{Análise das Temáticas dos Artigos Científicos em Sistemas de Informaçăo no Brasil}

Analisa-se aqui, a partir dos dados apresentados no Quadro 1, a relação entre os artigos científicos baseados em pesquisas empíricas e os ensaios teóricos e, também, os temas abordados nos artigos. 
Em termos da relação entre artigos empíricos e conceituais (vide Figura 1), em 90/91 mais de $60 \%$ dos artigos eram conceituais. A partir de 92/93 inverte-se esta relação, estabilizando-se em $63 \%$ e 37\% entre 92 e 95. Em 96/97 a diferença se acentua, com $66 \%$ dos artigos baseados em pesquisa empírica e com $34 \%$ conceituais, o que denota certa consolidação da produção de conhecimento local.

Figura 1: Evolução dos Temas Abordados

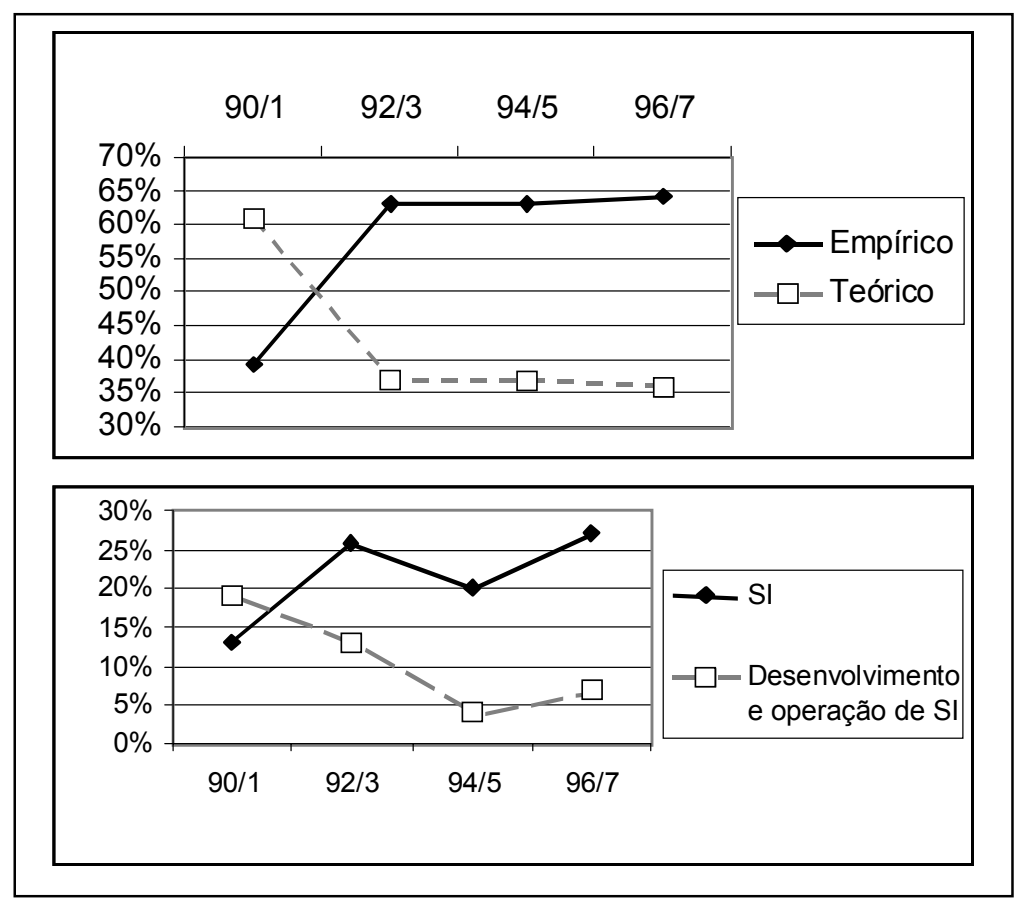

Os três grupos de temas (nível 1 da classificação) mais presentes nos artigos (mais de 60\%) são: E - Administração de SI, compreendendo essencialmente os temas avaliação, planejamento, organização e implicações gerenciais de SI; G Uso de SI, abrangendo os temas uso organizacional e tipos de suporte de SI; e H - SI, incluindo áreas de aplicação e tipos de SI (vide Figura 2).

Os cinco temas (nível 2 da classificação) mais citados (AC - Teoria da Decisão, EI - Avaliação de SI, GA - Uso Organizacional de SI, HA - Tipos de SI e HB Áreas de Aplicação de SI) concentram mais de 47\% dos artigos. Nota-se uma predominância dos temas referentes ao desenvolvimento, uso e validação de sistemas (protótipos) nas empresas, com 34\% envolvendo os itens Tipos de SI, Áreas de Aplicação e Uso de SI nas Organizações. 


\section{Figura 2: Distribuição Total de Artigos por Tema}

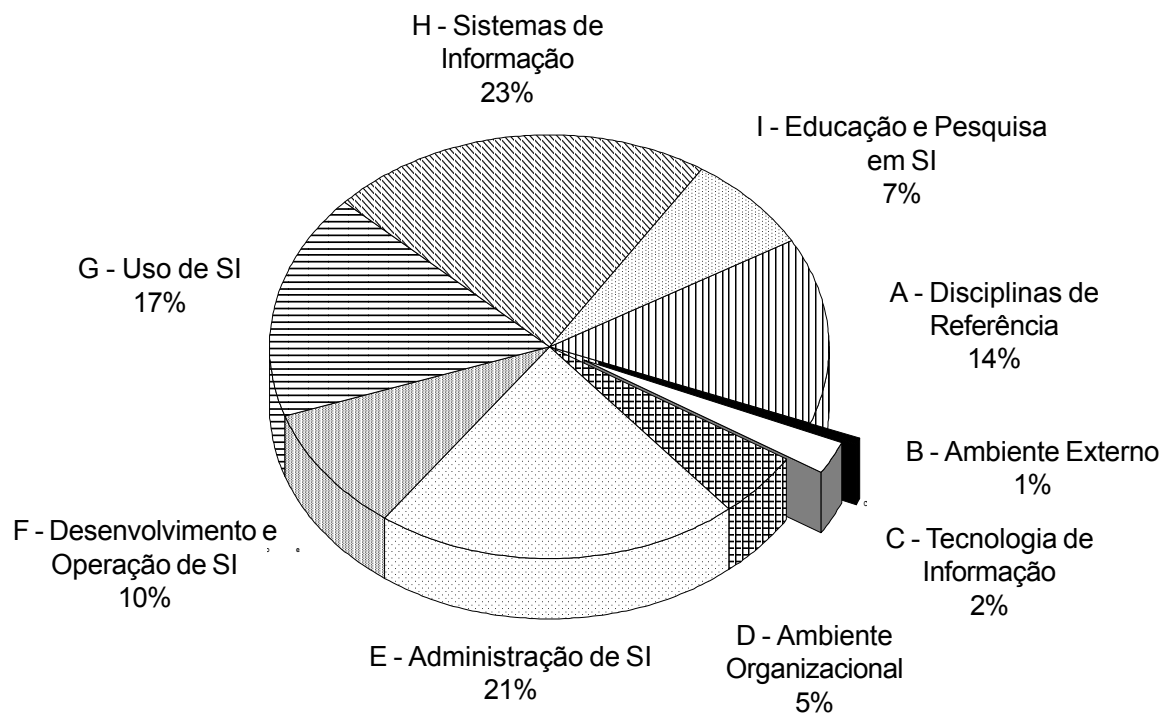

Considerando-se exclusivamente as pesquisas empíricas, o percentual dos grupos mais citados (E - Administração de SI, G - Uso de SI e H - Sistemas de Informação) sobe para $80 \%$. Analisando-se somente os ensaios teóricos, nota-se o crescimento elevado dos temas A - Disciplinas de Referência e I - Educação e Pesquisa em SI (vide Figura 3). Isto demonstra, nos ensaios teóricos, a preocupação de buscar em outras áreas do conhecimento informações relevantes para a área de SI.

Numa análise evolutiva dos temas entre 1990-1 e 1996-7, nota-se um crescimento dos temas do grupo H - SI (de 13 para $27 \%$ do total de artigos) e queda do grupo F - Desenvolvimento e Operação de SI (de 19 para 7\%) (vide Figura 1).

\section{Metodologias e Estratégias das Pesquisas em Sistemas de Informação}

A maior parte dos artigos (83\%) são de natureza exploratória (vide Quadro 2). Isto parece demonstrar falta de consolidação da área, que ainda se encontra em fase de formação da base conceitual para futuras teorias, e também mostra falta de continuidade nas linhas de pesquisa das Instituições. Deve-se salientar, ainda, que grande parte das estratégias explanatórias, assim classificadas em função do modelo e do desenho de pesquisa, foram consideradas (inadequadamente) pelos autores como sendo de natureza exploratória. 
Figura 3: Comparação entre Artigos de Pesquisa e Teóricos

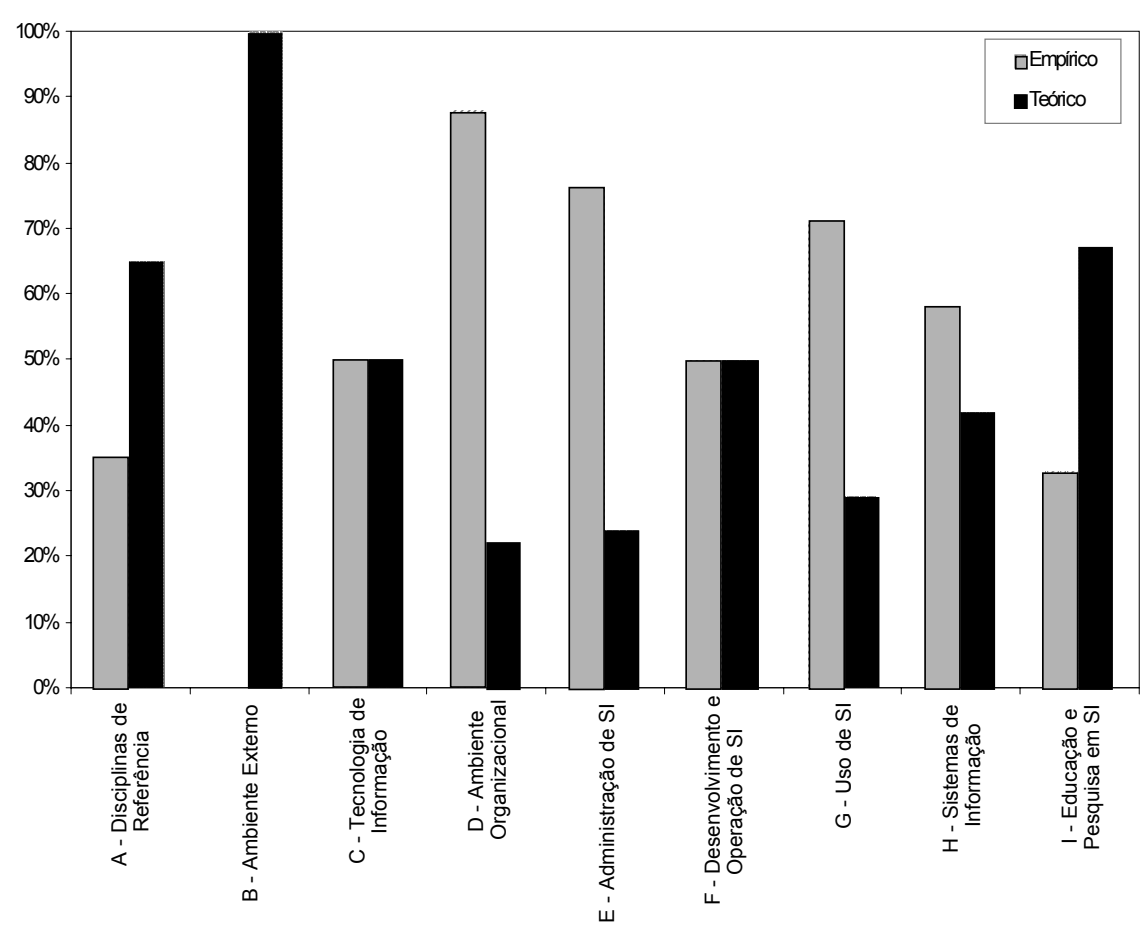

Quadro 2: Mapeamento das Estratégias e Metodologias

\begin{tabular}{|l|l|l|l|l|l|}
\hline \multicolumn{1}{|c|}{ Períodos } & & & & & \\
Elementos & $\mathbf{9 0 - 9 1}$ & $\mathbf{9 2 - 9 3}$ & $\mathbf{9 4 - 9 5}$ & $\mathbf{9 6 - 9 7}$ & Total \\
\hline Estratégias & $\mathbf{1 2}$ & $\mathbf{2 4}$ & $\mathbf{3 1}$ & $\mathbf{2 9}$ & $\mathbf{9 6}$ \\
\hline Exploratória & 9 & 18 & 30 & 23 & $80(83 \%)$ \\
\hline Descritiva & & 6 & 1 & 5 & $12(13 \%)$ \\
\hline Explanatória & 3 & & & 1 & $4 \quad(4 \%)$ \\
\hline Metodologias & $\mathbf{1 2}$ & $\mathbf{2 4}$ & $\mathbf{3 1}$ & $\mathbf{2 9}$ & $\mathbf{9 6}$ \\
\hline Pesquisa Survey & 6 & 5 & 11 & 13 & $35(36 \%)$ \\
\hline Pesquisa Experimental & 1 & 1 & 7 & 1 & $10(10 \%)$ \\
\hline Pesquisa Qualitativa & & & & & \\
\hline - Caso & 2 & 13 & 10 & 8 & $33(34 \%)$ \\
\hline - Pesquisa-ação & 3 & 4 & 2 & 4 & $13(14 \%)$ \\
\hline - Outros & 0 & 1 & 1 & 3 & $5 \quad(6 \%)$ \\
\hline
\end{tabular}


Quanto às metodologias de pesquisa adotadas, verifica-se uma predominância das qualitativas (54\%). Os estudos de caso representam 34\% do total e as pesquisas survey $36 \%$, sendo a metodologia experimental pouco utilizada. O uso destas metodologias é coerente com a estratégia exploratória que predomina.

\section{Análise da Qualidade Científica dos Artigos de Pesquisa em Sistemas de Informação}

A (boa) qualidade de um artigo científico é definida a partir de teorias e conceitos de base aprofundados, objetivos definidos, questões de pesquisa ou hipóteses explicitadas, modelo de pesquisa definido com clareza, indicação de operacionalização das variáveis mensuradas, a utilização de amostras aleatórias (nas pesquisas survey e experimentais), a validação de face e dos construtos e a determinação da confiabilidade dos instrumentos de pesquisa (quando se aplica), a pertinência dos testes estatísticos, a explicitação do protocolo de análise (nas pesquisas qualitativas e experimentais), a interpretação aprofundada dos dados, a indicação dos limites do estudo e a apresentação de recomendações. A seguir analisa-se a qualidade científica dos artigos que utilizam cada um dos três tipos de metodologia.

\section{Pesquisas Survey}

A análise dos artigos que utilizam a pesquisa survey como metodologia apresenta a seguinte situação (vide Quadro 3):

. somente $20 \%$ apresentam teorias e conceitos de base aprofundados e $57 \%$ explicitam as questões ou hipóteses de pesquisa;

. somente $31 \%$ possuem um modelo de pesquisa definido claramente e $46 \%$ explicitam a operacionalização das variáveis;

. somente $43 \%$ têm amostras estruturadas aleatoriamente;

. em $54 \%$ dos casos não apresentam informações sobre a validade de face, $77 \%$ sobre a confiabilidade e $86 \%$ sobre a validade do construto;

$.60 \%$ apresentam recomendações e limites do estudo.

A quase totalidade das pesquisas utilizam dados primários. Somente $17 \%$ utilizam dados secundários, sendo que a maior parte junto com dados primários. Isto parece demonstrar pouca disponibilidade ou confiabilidade na utilização de outras fontes de consulta (banco de dados, publicações legais, etc). 
Com base nestes elementos, a qualidade dos artigos científicos que utilizam a pesquisa survey como metodologia pode ser caracterizada como baixa-média.

\section{Quadro 3: Análise da Qualidade das Pesquisas do Tipo Survey}

\begin{tabular}{|c|c|c|c|c|c|}
\hline \multirow[t]{2}{*}{ Elementos de análise } & \multicolumn{5}{|c|}{ Períodos } \\
\hline & $90-91$ & $92-93$ & 94-95 & 96-97 & TOTAL \\
\hline \multicolumn{6}{|l|}{ 1. EMBASAMENTO CONCEITUAL } \\
\hline $\begin{array}{c}\text { Teorias e conceitos de base: aprofundado } \\
\text { superficial } \\
\text { ausente }\end{array}$ & $\begin{array}{l}3 \\
2\end{array}$ & $\begin{array}{l}2 \\
1 \\
2\end{array}$ & $\begin{array}{l}4 \\
5 \\
2\end{array}$ & $\begin{array}{l}7 \\
2 \\
4\end{array}$ & $\begin{array}{l}7(20 \%) \\
10 \\
18\end{array}$ \\
\hline $\begin{array}{r}\text { Objetivos: sim } \\
\text { não }\end{array}$ & 6 & 5 & 11 & $\begin{array}{r}11 \\
2 \\
\end{array}$ & $\begin{array}{l}33 \\
2 \\
\end{array}$ \\
\hline $\begin{array}{ll}\text { Questão de pesquisa, hipóteses: } & \text { sim } \\
\text { ou pressupostos de base } & \text { não } \\
\end{array}$ & 6 & $\begin{array}{l}3 \\
2\end{array}$ & $\begin{array}{l}4 \\
7\end{array}$ & $\begin{array}{l}7 \\
6\end{array}$ & $\begin{array}{ll}20 & (57 \%) \\
15 & \end{array}$ \\
\hline \multicolumn{6}{|l|}{ 2. DESENHO DE PESOUISA } \\
\hline $\begin{array}{r}\text { Modelo de pesquisa : } \\
\text { sim - com clareza } \\
\text { sim - pouca clareza } \\
\text { não }\end{array}$ & $\begin{array}{l}4 \\
2\end{array}$ & 3 & $\begin{array}{l}2 \\
5 \\
4 \\
\end{array}$ & $\begin{array}{l}3 \\
5 \\
5 \\
\end{array}$ & $\begin{array}{ll}11 & (31 \%) \\
12 & \\
12 & \\
\end{array}$ \\
\hline $\begin{array}{r}\text { Operacionalização das variáveis: sim } \\
\text { não }\end{array}$ & $\begin{array}{l}3 \\
3\end{array}$ & $\begin{array}{l}4 \\
1\end{array}$ & $\begin{array}{l}3 \\
8\end{array}$ & $\begin{array}{l}6 \\
7\end{array}$ & $\begin{array}{ll}16 \quad(46 \%) \\
19\end{array}$ \\
\hline \multicolumn{6}{|l|}{ 3. COLETA DOS DADOS } \\
\hline $\begin{array}{l}\text { Tipo de dados: primários } \\
\text { Secundários } \\
\text { Primário + secundário }\end{array}$ & 2 & 1 & $\begin{array}{r}10 \\
1 \\
\end{array}$ & $\begin{array}{r}10 \\
1 \\
2 \\
\end{array}$ & $\begin{array}{l}28 \\
1 \\
6 \\
\end{array}$ \\
\hline $\begin{array}{l}\text { Tipo de amostra: aleatória } \\
\text { Intencional }\end{array}$ & 6 & $\begin{array}{l}4 \\
1 \\
\end{array}$ & $\begin{array}{l}6 \\
5\end{array}$ & $\begin{array}{l}5 \\
8\end{array}$ & $\begin{array}{ll}15 & (43 \%) \\
20 & \end{array}$ \\
\hline \multicolumn{6}{|l|}{ 4. VALIDADE } \\
\hline $\begin{array}{r}\text { de Face: } \operatorname{sim} \\
\text { não } \\
\end{array}$ & $\begin{array}{l}3 \\
3 \\
\end{array}$ & $\begin{array}{l}2 \\
3 \\
\end{array}$ & $\begin{array}{l}4 \\
7 \\
\end{array}$ & $\begin{array}{l}7 \\
6 \\
\end{array}$ & $\begin{array}{ll}16 & \\
19 \quad(54 \%) \\
\end{array}$ \\
\hline $\begin{array}{r}\text { Confiabilidade: sim } \\
\text { não }\end{array}$ & 6 & $\begin{array}{l}2 \\
3 \\
\end{array}$ & $\begin{array}{l}3 \\
8 \\
\end{array}$ & $\begin{array}{r}3 \\
10 \\
\end{array}$ & $\begin{array}{ll}8 & \\
27 & (77 \%) \\
\end{array}$ \\
\hline $\begin{array}{r}\text { do Construto: sim } \\
\text { não }\end{array}$ & $\begin{array}{l}2 \\
4\end{array}$ & $\begin{array}{l}1 \\
4\end{array}$ & 11 & $\begin{array}{r}2 \\
11\end{array}$ & $\begin{array}{ll}5 & \\
30 \quad(86 \%)\end{array}$ \\
\hline \multicolumn{6}{|l|}{ 5. ANÁLISE DOS DADOS } \\
\hline $\begin{array}{r}\text { Pertinência dos testes estatísticos: sim } \\
\text { não }\end{array}$ & 6 & 5 & $\begin{array}{l}7 \\
4 \\
\end{array}$ & $\begin{array}{l}9 \\
4\end{array}$ & $\begin{array}{l}27 \\
8\end{array}$ \\
\hline \multicolumn{6}{|l|}{ 6. APRESENTAÇÃO DOS RESULTADOS } \\
\hline $\begin{array}{l}\text { Limites estudo/recomendações: sim } \\
\text { não }\end{array}$ & $\begin{array}{l}5 \\
1\end{array}$ & 5 & $\begin{array}{l}5 \\
6 \\
\end{array}$ & $\begin{array}{l}6 \\
7\end{array}$ & $\begin{array}{ll}21 \quad(60 \%) \\
14\end{array}$ \\
\hline
\end{tabular}

\section{Pesquisa Experimental}

A análise dos artigos que utilizam a pesquisa experimental como metodologia apresenta o seguinte panorama (vide Quadro 4): 


\section{Quadro 4: Análise da Qualidade das Pesquisas Experimentais}

\begin{tabular}{|c|c|c|c|c|c|}
\hline \multirow[t]{2}{*}{ Elementos de análise } & \multicolumn{5}{|c|}{ Períodos } \\
\hline & $90-91$ & $92-93$ & $\begin{array}{l}94- \\
95\end{array}$ & $\begin{array}{l}96- \\
97\end{array}$ & TOTAL \\
\hline \multicolumn{6}{|l|}{ 1. EMBASAMENTO CONCEITUAL } \\
\hline $\begin{array}{c}\text { Teorias e conceitos de base: aprofundado } \\
\text { superficial } \\
\text { ausente }\end{array}$ & 1 & 1 & $\begin{array}{l}3 \\
4\end{array}$ & 1 & $\begin{array}{ll}4 & (40 \%) \\
6 & \end{array}$ \\
\hline $\begin{array}{r}\text { Objetivos : sim } \\
\text { não }\end{array}$ & 1 & 1 & $\begin{array}{l}6 \\
1 \\
\end{array}$ & 1 & $\begin{array}{l}9 \\
1 \\
\end{array}$ \\
\hline $\begin{array}{ll}\text { Questão de pesquisa, hipóteses: } & \text { sim } \\
\text { ou pressupostos de base } & \text { não }\end{array}$ & 1 & 1 & $\begin{array}{l}3 \\
4\end{array}$ & 1 & $\begin{array}{l}4 \\
6\end{array}$ \\
\hline \multicolumn{6}{|l|}{ 2. DESENHO DE PESQUISA } \\
\hline $\begin{array}{l}\text { Modelo de pesquisa : } \operatorname{sim} \text { - com clareza } \\
\text { sim - pouca clareza } \\
\text { não } \\
\end{array}$ & 1 & 1 & \begin{tabular}{l|}
3 \\
1 \\
3 \\
\end{tabular} & 1 & $\begin{array}{ll}3 & (30 \%) \\
1 & \\
6 & \\
\end{array}$ \\
\hline $\begin{aligned} \text { Desenho Experimental: adequado } \\
\text { não adequado }\end{aligned}$ & 1 & 1 & $\begin{array}{l}4 \\
3 \\
\end{array}$ & 1 & \begin{tabular}{|ll}
7 & $(70 \%)$ \\
3 & \\
\end{tabular} \\
\hline $\begin{array}{r}\text { Operacionalização das variáveis: sim } \\
\text { não }\end{array}$ & 1 & 1 & $\begin{array}{l}4 \\
3 \\
\end{array}$ & 1 & \begin{tabular}{|ll}
5 & $(50 \%)$ \\
5 & \\
\end{tabular} \\
\hline $\begin{array}{r}\text { Controle Experimental: bom rigor } \\
\text { pouco rigor }\end{array}$ & 1 & 1 & $\begin{array}{l}5 \\
2 \\
\end{array}$ & 1 & $\begin{array}{l}7 \\
3 \\
\end{array}$ \\
\hline \multicolumn{6}{|l|}{ 3. COLETA DOS DADOS } \\
\hline $\begin{array}{r}\text { Tipo de dados: primários } \\
\text { secundários }\end{array}$ & 1 & 1 & $\begin{array}{l}6 \\
1 \\
\end{array}$ & 1 & $\begin{array}{l}7 \\
3 \\
\end{array}$ \\
\hline $\begin{array}{r}\text { Tipo de amostra: aleatória } \\
\text { intencional }\end{array}$ & 1 & 1 & $\begin{array}{l}1 \\
6 \\
\end{array}$ & 1 & $\begin{array}{ll}3 & (30 \%) \\
7 & \end{array}$ \\
\hline \multicolumn{6}{|l|}{ 4. VALIDADE } \\
\hline $\begin{array}{r}\text { de Face: } \operatorname{sim} \\
\text { não }\end{array}$ & 1 & 1 & $\begin{array}{l}2 \\
5 \\
\end{array}$ & 1 & $\begin{array}{|ll|}2 & \\
8 & (80 \%) \\
\end{array}$ \\
\hline $\begin{array}{r}\text { Confiabilidade: sim } \\
\text { não }\end{array}$ & 1 & 1 & $\begin{array}{l}3 \\
4 \\
\end{array}$ & 1 & $\begin{array}{ll}3 & \\
7 & (70 \%) \\
\end{array}$ \\
\hline $\begin{array}{r}\text { do Construto: sim } \\
\text { não }\end{array}$ & 1 & 1 & $\begin{array}{l} \\
6 \\
\end{array}$ & 1 & \begin{tabular}{|ll}
1 & \\
9 & $(90 \%)$ \\
\end{tabular} \\
\hline \multicolumn{6}{|l|}{ 5. ANÁLISE DOS DADOS } \\
\hline $\begin{array}{r}\text { Pertinência dos testes estatísticos: } \\
\text { sim não } \\
\end{array}$ & 1 & 1 & $\begin{array}{l}3 \\
4 \\
\end{array}$ & 1 & \begin{tabular}{|ll}
5 & $(50 \%)$ \\
5 &
\end{tabular} \\
\hline \multicolumn{6}{|l|}{ 6. APRESENTACุÃO DOS RESULTADOS } \\
\hline $\begin{array}{l}\text { Limites estudo/recomendações: sim } \\
\text { não }\end{array}$ & 1 & 1 & $\begin{array}{l}6 \\
1\end{array}$ & 1 & $\begin{array}{ll}9 & (90 \%) \\
1 & \end{array}$ \\
\hline
\end{tabular}

. somente $40 \%$ apresentam teorias e conceitos de base aprofundados e detalham as questões ou hipóteses de pesquisa;

. somente $30 \%$ possuem um modelo de pesquisa definido claramente, $70 \%$ têm desenho experimental adequado e controle experimental rigoroso, e $50 \%$ explicitam a operacionalização das variáveis;

. somente $30 \%$ têm amostras estruturadas aleatoriamente;

$.80 \%$ não apresenta informações referentes à validade de face, $70 \%$ sobre a confiabilidade e $90 \%$ sobre a validade do construto; 
$.50 \%$ dos testes estatísticos são pertinentes;

$.90 \%$ apresentam recomendações e limites do estudo.

Com base nesses elementos, pode-se afirmar que a qualidade dos artigos científicos que utilizam a pesquisa experimental como metodologia também pode ser classificada como baixa-média.

\section{Pesquisas Qualitativas}

\section{Quadro 5: Análise da Qualidade das Pesquisas Qualitativas}

\begin{tabular}{|c|c|c|c|c|c|}
\hline \multirow[t]{2}{*}{ Elementos de análise } & \multicolumn{5}{|c|}{ Períodos } \\
\hline & 90-91 & $92-93$ & 94-95 & 96-97 & TOTAL \\
\hline $\begin{array}{c}\text { 1. POSIÇÃO EPISTEMOLÓGICA } \\
\text { Positivista } \\
\text { Interpretativa } \\
\end{array}$ & $\begin{array}{l}4 \\
1 \\
\end{array}$ & $\begin{array}{r}16 \\
2 \\
\end{array}$ & $\begin{array}{l}7 \\
6 \\
\end{array}$ & $\begin{array}{r}11 \\
4 \\
\end{array}$ & $\begin{array}{ll}38 & (75 \%) \\
13 & (25 \%) \\
\end{array}$ \\
\hline \multicolumn{6}{|l|}{ 2. EMBASAMENTO CONCEITUAL } \\
\hline $\begin{array}{c}\text { Teorias e conceitos de base: aprofundado } \\
\text { superficial } \\
\text { ausente }\end{array}$ & $\begin{array}{l}1 \\
3 \\
1 \\
\end{array}$ & $\begin{array}{r}1 \\
16 \\
1 \\
\end{array}$ & $\begin{array}{l}5 \\
5 \\
3 \\
\end{array}$ & $\begin{array}{l}6 \\
7 \\
2 \\
\end{array}$ & $\begin{array}{ll}13 & (25 \%) \\
31 & \\
7 & \\
\end{array}$ \\
\hline $\begin{array}{r}\text { Objetivos : sim } \\
\text { não }\end{array}$ & $\begin{array}{l}4 \\
1 \\
\end{array}$ & $\begin{array}{r}16 \\
2 \\
\end{array}$ & $\begin{array}{r}10 \\
3 \\
\end{array}$ & $\begin{array}{r}12 \\
3 \\
\end{array}$ & $\begin{array}{l}42 \\
9 \\
\end{array}$ \\
\hline $\begin{array}{ll}\text { Questão de pesquisa, hipóteses: } & \text { sim } \\
\text { ou pressupostos de base } & \text { não }\end{array}$ & $\begin{array}{l}3 \\
2\end{array}$ & $\begin{array}{r}7 \\
11\end{array}$ & $\begin{array}{r}3 \\
10\end{array}$ & $\begin{array}{l}8 \\
7\end{array}$ & $\begin{array}{ll}21 & (41 \%) \\
30 & \end{array}$ \\
\hline \multicolumn{6}{|l|}{ 3. DESENHO DE PESOUISA } \\
\hline $\begin{array}{l}\text { Modelo de Pesquisa: sim - com clareza } \\
\text { sim - pouca clareza } \\
\text { não } \\
\end{array}$ & $\begin{array}{l}2 \\
1 \\
2 \\
\end{array}$ & $\begin{array}{l}7 \\
8 \\
3 \\
\end{array}$ & $\begin{array}{l}2 \\
2 \\
9 \\
\end{array}$ & \begin{tabular}{r|r}
3 \\
2 \\
10 \\
\end{tabular} & $\begin{array}{ll}14 & (27 \%) \\
13 & \\
24 & \\
\end{array}$ \\
\hline $\begin{array}{l}\text { Tipo de Metodologia: caso } \\
\text { pesquisa-ação } \\
\text { outros } \\
\end{array}$ & $\begin{array}{l}2 \\
3\end{array}$ & $\begin{array}{r}13 \\
4 \\
1 \\
\end{array}$ & $\begin{array}{r}10 \\
2 \\
1 \\
\end{array}$ & $\begin{array}{l}8 \\
4 \\
3 \\
\end{array}$ & \begin{tabular}{|l}
33 \\
13 \\
5 \\
\end{tabular} \\
\hline $\begin{array}{r}\text { Unidade de Análise: sim } \\
\text { não }\end{array}$ & 5 & 18 & $\begin{array}{r}12 \\
1 \\
\end{array}$ & $\begin{array}{r}13 \\
2 \\
\end{array}$ & $\begin{array}{l}48 \\
3 \\
\end{array}$ \\
\hline \multicolumn{6}{|l|}{ 4. COLETA DOS DADOS } \\
\hline $\begin{array}{r}\text { Entrevista: } \operatorname{sim}_{\text {não }} \\
\end{array}$ & $\begin{array}{l}1 \\
4 \\
\end{array}$ & $\begin{array}{l}9 \\
9 \\
\end{array}$ & $\begin{array}{l}6 \\
7 \\
\end{array}$ & $\begin{array}{r}5 \\
10 \\
\end{array}$ & $\begin{array}{l}21 \\
30 \\
\end{array}$ \\
\hline $\begin{array}{r}\text { Questionário: sim } \\
\text { não }\end{array}$ & $\begin{array}{l}1 \\
4 \\
\end{array}$ & $\begin{array}{r}4 \\
14 \\
\end{array}$ & $\begin{array}{r}3 \\
10 \\
\end{array}$ & $\begin{array}{r}2 \\
13 \\
\end{array}$ & $\begin{array}{l}10 \\
41 \\
\end{array}$ \\
\hline $\begin{array}{r}\text { Multimétodos: sim } \\
\text { não }\end{array}$ & $\begin{array}{l}1 \\
4 \\
\end{array}$ & $\begin{array}{r}7 \\
11 \\
\end{array}$ & $\begin{array}{r}1 \\
12 \\
\end{array}$ & $\begin{array}{r}4 \\
11 \\
\end{array}$ & $\begin{array}{l}13 \\
38 \\
\end{array}$ \\
\hline $\begin{array}{r}\text { Dados secundários: sim } \\
\text { não }\end{array}$ & 5 & $\begin{array}{r}4 \\
14 \\
\end{array}$ & $\begin{array}{r}2 \\
11 \\
\end{array}$ & 15 & $\begin{array}{ll}6 & (12 \%) \\
45 & \end{array}$ \\
\hline \multicolumn{6}{|l|}{ 5. ANÁLISE DOS DADOS } \\
\hline $\begin{array}{l}\text { Protocolo de Análise: explicitado } \\
\text { não explicitado }\end{array}$ & $\begin{array}{l}3 \\
5 \\
\end{array}$ & $\begin{array}{r}12 \\
6 \\
\end{array}$ & $\begin{array}{r}3 \\
10 \\
\end{array}$ & $\begin{array}{r}2 \\
13 \\
\end{array}$ & $\begin{array}{ll}20 & (39 \%) \\
31 & \\
\end{array}$ \\
\hline \multicolumn{6}{|l|}{ 6. APRESENTACCÃO DOS RESULTADOS } \\
\hline $\begin{array}{l}\text { Interpretação dos dados: profunda } \\
\text { superficial }\end{array}$ & $\begin{array}{l}3 \\
2\end{array}$ & $\begin{array}{r}8 \\
10\end{array}$ & $\begin{array}{l}7 \\
6\end{array}$ & $\begin{array}{l}8 \\
7\end{array}$ & $\begin{array}{l}26 \\
25\end{array}$ \\
\hline $\begin{array}{r}\text { Limites estudo/recomendações: sim } \\
\text { não }\end{array}$ & 5 & $\begin{array}{r}16 \\
2\end{array}$ & $\begin{array}{r}3 \\
10\end{array}$ & $\begin{array}{l}6 \\
9\end{array}$ & $\begin{array}{ll}30 & (59 \%) \\
21 & \end{array}$ \\
\hline
\end{tabular}


A análise dos artigos que utilizam as pesquisas qualitativas como metodologia apresenta o seguinte panorama (vide Quadro 5):

$.75 \%$ das pesquisas possuem posição epistemológica positivista, enquanto que $25 \%$ possuem posição epistemológica interpretativa. É interessante salientar que o número de pesquisas de posição interpretativa é significativo, considerando a forte base positivista da pesquisa em SI no Brasil (Rodrigues et al.,1998);

. somente $25 \%$ apresentam teorias e conceitos de base aprofundados e $41 \%$ detalham as questões de pesquisa;

$.27 \%$ somente possuem um modelo de pesquisa definido claramente;

. menos de $12 \%$ utilizam dados secundários;

. somente $39 \%$ têm o protocolo de análise dos dados explicitado;

$.59 \%$ apresentam recomendações e limites do estudo.

Com base nestes elementos, pode-se afirmar, mais uma vez que, a qualidade dos artigos científicos que utilizam as pesquisas qualitativas como metodologia também pode ser caracterizada como baixa-média.

\section{Conclusóes e Implicações para Pesquisas Futuras}

Nesta seção apresentam-se as conclusões, os limites e as implicações do estudo.

\section{Temas Preferenciais dos Artigos}

Os temas abordados com maior freqüência nos artigos científicos no Brasil, no período 1990-97, foram os relacionados à administração de SI, ao uso de SI e aos SI propriamente ditos. Estes temas configuram um mapeamento do desenvolvimento e uso dos SI no Brasil, evidenciando assim características próprias ao contexto local. Cabe salientar que a proporção de estudos conceituais ( $41 \%$ no período todo e 34\% no período 1996-7) ainda é alta para um domínio que quer estabelecer-se como área de conhecimento. Além disso, praticamente não há estudos comparativos com realidades de outros países. Temas atuais, como impacto econômico e social dos SI nas organizações e na sociedade, ainda são tratados de modo incipiente. Por outro lado, os $14 \%$ de artigos que abordam temas de referência mostram que a disciplina tem fortes conexões com outras áreas do conhecimento, e os $6 \%$ de artigos que tratam da pesquisa em SI atestam a preocupação de consolidar a área. 


\section{Metodologias, Estratégias de Pesquisa e Qualidade dos Artigos}

Com base nos artigos analisados, sentiu-se a carência de uma melhor descrição das metodologias de pesquisa. Mesmo em pesquisas de caráter exploratório a sua explicitação é importante, por permitir a divulgação do modo de obtenção do conhecimento. Este detalhamento metodológico é muito útil na replicação das pesquisas, porque permite aprofundar mais os temas. Constatou-se, também, a existência de problemas na definição das metodologias de pesquisa, principalmente nas pesquisas qualitativas. Um exemplo disto é que muitas vezes os autores denominam de estudo de caso o estudo em que o pesquisador intervém nas organizações (mais adequadamente conceituado como pesquisa-ação).

Também se constata má interpretação do que são as estratégias de pesquisa, especialmente as do tipo explanatório. Nestas, foram detalhados conceitos de base, hipóteses e desenho de pesquisa que contempla teste de hipóteses. Apesar disso os autores as denominaram exploratórias em seus artigos, evidenciando um equívoco quanto à compreensão do que seja este tipo de estratégia.

De modo geral, identificou-se uma qualidade científica média-baixa nos artigos baseados em pesquisa empírica, como conseqüência do pouco rigor no que se refere ao desenho de pesquisa e à validade dos instrumentos (em todos os tipos de pesquisa). Isto demonstra certa falta de cuidado com relação ao rigor científico no desenvolvimento das pesquisas ou falta de informações importantes na apresentação dos resultados nos artigos.

Como aspecto favorável, constatou-se que a maior parte dos artigos, em todos os tipos de pesquisa, apresentam os objetivos dos estudos desenvolvidos.

\section{Limites do Estudo}

A amostra restringiu-se a artigos científicos publicados em veículos da área de Administração. Como já mencionado, dos Anais do ENANPAD analisaram-se somente artigos do volume Administração da Informação, com três exceções. A amostra também não contém outros veículos de domínios conexos da Administração, como os Anais do ENEGEP ou revistas científicas da área de Sociologia, Economia, Engenharia e Informática. Mesmo assim, atingiu-se o expressivo número de 163 artigos analisados.

Outro aspecto que importa mencionar é a utilização de um só tema (palavrachave) na classificação dos artigos. Ficou evidenciado que, muitas vezes, o uso de 2 ou 3 palavras-chaves tornaria esta classificação mais clara, o que, por outro lado, inviabilizaria a análise dos temas preferenciais da maneira como foi efetuada neste estudo. 
Finalmente, cabe mencionar que, para reduzir a subjetividade da análise dos pesquisadores (até certo ponto natural neste tipo de estudo), foi feito um treinamento em termos de uso da metodologia de análise durante a disciplina Métodos de Pesquisa em SI (mediante a análise de aproximadamente 10 artigos por parte de cada um dos participantes) e foram realizadas duas reuniões de harmonização da classificação e análise.

\section{Contribuiçőes e Implicações para Pesquisas Futuras em Sistemas de Informaçăo}

A principal contribuição deste artigo consistiu em apresentar um panorama relativamente completo dos artigos científicos, empíricos e teóricos, no Brasil, que pode ser útil para as instituições de pesquisa e para os comitês editoriais das principais revistas científicas. Para as primeiras, permite reorientar as estratégias das pesquisas (linhas de pesquisa mais bem definidas, pesquisas cumulativas, redução das pesquisas de caráter exploratório). A diminuição da aceitação de ensaios teóricos nas revistas também deve contribuir para acelerar a consolidação da área de SI como área de conhecimento autônomo.

Como pesquisas futuras a serem realizadas a partir deste estudo, poder-se-iam estabelecer comparações com estudos realizados em outros países, permitindo cotejar os temas, as tendências e a qualidade dos artigos, o que ajudaria a situar a área de SI no Brasil em relação a outros países, como, por exemplo, os Estados Unidos.

\section{Notas}

1 Este artigo contém os resultados de um estudo coletivo efetuado na disciplina Métodos de Pesquisa em Sistemas de Informação no PPGA-UFRGS, turma 97. Participaram da elaboração do mesmo os alunos: Amarolinda Costa Zanela, André Moraes Santos, Clarissa Tarragô Candotti, Jorge Luiz Nicolas Audy, Maira Petrini, Marcelo Gattermann Perin, Marlei Salete Mecca e Roberto Scheid. A colaboração das bolsistas Fabiana Böhm Gramkow, Adriana Bastiani Guggiana e Cleonice Cardoso dos Santos e o apoio do CNPq foram decisivos para a sua concretização.

${ }^{2}$ Neste quadro somente estão apresentados os temas identificados nos artigos analisados. A classificação completa encontra-se em Barki et al. (1993). 


\section{BibLIOGRAFIA}

AGUIAR, L. C. S.;

KELM, M. L.

Tecnologia informacional no contexto dos negócios cambiais : um estudo de caso. In: XVI ENCONTRO ANUAL DA ANPAD (1992 : Canela). Anais... Porto Alegre: ANPAD, 1992.

AGUIAR, L. C. S.;

HOPPEN, N.

A difusão da tecnologia da informação na área de câmbio dos bancos no Brasil. In: XVII ENCONTRO ANUAL DA ANPAD (1993 : Salvador). Anais... Salvador: ANPAD, 1993.

\section{ALBERTIN, A. L.}

Administração de informática : um estudo sobre seus fatores críticos de sucesso no setor bancário privado nacional. In: XVII ENCONTRO ANUAL DA ANPAD (1993 : Salvador). Anais... Salvador : ANPAD, 1993.

Administração da informática e a organização. Revista de Administração de Empresas, v. 34, n. 6, 1994.

Aumentando as chances de sucesso no desenvolvimento e implementação de sistemas de informações. Revista de Administração de Empresas, v. 36, n. 3, 1996.

Comércio eletrônico. In: XXI ENCONTRO ANUAL DA ANPAD (1997 : Angra dos Reis). Anais Eletrônicos... Rio de Janeiro : ANPAD, 1997.

ALBERTIN, A. L. et al. Administração de informática e a organização. Revista Brasileira de Administração Contemporânea, v. 1, n. 4, 1995.

ALBERTIN, A. L.;

MOURA, R. M.

Administração de informática e seus fatores críticos de sucesso no setor bancário privado nacional. Revista de Administração de Empresas, v. 35, n. 5, 1995.

ALBINO, J. P.

OEA : uma ferramenta para trabalho em grupo. In: XVII ENCONTRO ANUAL DA ANPAD (1993 : Salvador). Anais... Salvador : ANPAD, 1993.

ALMEIDA, A. T.;

ALCOFORADO, M. M. D. G.

Apoio à decisão no planejamento e administração de sistemas de informação. In: XX ENCONTRO ANUAL DA ANPAD (1996 : Angra dos Reis). Anais... Rio de Janeiro : ANPAD, 1996.

ALMEIDA, F. C.

Aplicação de redes neurais no apoio à decisão : um estudo aplicado à identificação de risco de falência.In: XVI ENCONTRO ANUAL DA ANPAD (1992 : Canela). Anais... Porto Alegre : ANPAD, 1992.

Atores e fatores na introdução de um sistema de informação. Revista Brasileira de Administração Contemporânea, v. 1, n. 4, 1995.

Sistemas de informação executiva : modelando e implementando um sistema de fluxo de caixa de longo prazo. In: XXI ENCONTRO ANUAL DA ANPAD (1997 : Angra dos Reis). Anais Eletrônicos... Rio de Janeiro : ANPAD, 1997. 
ALMEIDA, F. C.;

DUMONTIER, $P$.

$\mathrm{O}$ uso de redes neurais em avaliação de riscos de inadimplência.

Revista de Administraçã̃o, v. 31, n. 1, 1996.

\section{ANTUNES, A.}

Seleção de aplicações práticas de sistemas especialistas. In: XIV ENCONTRO ANUAL DA ANPAD (1990 : Florianólis). Anais... Florianópolis : ANPAD, 1990.

ANTUNES, A.;

HOPPEN, N.

O tempo do especialista no processo de desenvolvimento de sistemas especialistas : uma proposta de otimização. In: XV ENCONTRO ANUAL DA ANPAD (1991 : Belo Horizonte). Anais... Belo Horizonte : ANPAD, 1991.

ASPER, G. J.

Estratégias para a difusão de tecnologias da informação : um instrumento de análise a serviço dos executivos de informática e gerentes de projetos. In: XV ENCONTRO ANUAL DA ANPAD (1991 : Belo Horizonte). Anais... Belo Horizonte : ANPAD, 1991.

ASPER, G. J. et al.

Perspectivas de implementação da tecnologia de reuniões eletrônicas na Câmara de Pesquisa e PósGraduação da Universidade de Brasília, no contexto da difusão de inovações. In: XX ENCONTRO ANUAL DA ANPAD (1996 : Angra dos Reis). Anais... Rio de Janeiro : ANPAD, 1996.

ASPER, G. J;

CASTRO, L. H. R.

Inovações interativas, comunicação e difusão de inovações no meio acadêmico. In: XXI ENCONTRO ANUAL DA ANPAD (1997 : Angra dos Reis). Anais Eletrônicos... Rio de Janeiro : ANPAD, 1997.

BARKI, H. et al.

An information systems classification scheme : an update. MIS Quarterly, p. 209- 226, June 1993.

BELLOTI, R.

A gestão financeira como um fator de qualidade e competitividade nas instituições de ensino superior (uma proposta da Universidade de Passo Fundo). Revista Brasileira de Administração Contemporânea, v. 1, n. 4, 1995.

BIETHAHN, J.

Using SAP in education. In: XXI ENCONTRO ANUAL DA ANPAD (1997 : Angra dos Reis). Anais Eletrônicos... Rio de Janeiro : ANPAD, 1997.

BOFF, L. H.

Towards a comprehensive model of the knowledge work process. In: XX ENCONTRO ANUAL DA ANPAD (1996: Angra dos Reis). Anais... Rio de Janeiro : ANPAD, 1996.

BOFF, L. H. et al.

Adquirindo vantagem competitiva através de recursos de informação. In: XV ENCONTRO ANUAL DA ANPAD (1991: Belo Horizonte). Anais... Belo Horizonte : ANPAD, 1991.

Cenários atuais da comunicação eletrônica : um exemplo do uso de bases de dados e métodos de tratamento da informação. Revista Brasileira de Administração Contemporânea, v. 1, n. 4, 1995. 
BOFF, L. H.;

HOPPEN, N.

Correio eletrônico, trabalho cooperativo e gerência de informação: a integração a partir de estudo experimental. In: XVIII ENCONTRO ANUAL DA ANPAD (1994 : Curitiba). Anais... Curitiba : ANPAD, 1994.

BORENSTEIN, D.;

BECKER, J. L.

Simflex : um avaliador de sistemas flexíveis de manufatura. Revista de Administração, v. 29, n. 2, 1994.

\section{BRODBECK, A. F.}

Projeto SAI : uma experiência de automação do ensino de informática para administradores. In: XIV ENCONTRO ANUAL DA ANPAD (1990 Florianópolis). Anais... Florianópolis : ANPAD, 1990.

Desenvolvimento de um protótipo de sistema especialista na área de atendimento a usuários com comunicação remota. In: XVI ENCONTRO ANUAL DA ANPAD (1992 : Canela). Anais... Porto Alegre : ANPAD, 1992.

Avaliação da qualidade da informação nos sistemas de informações e de apoio à decisão - um estudo introdutório. Revista Brasileira de Administração Contemporânea, v. 1, n. 4, 1995.

Mudança de redirecionamento dos trabalhos em grupo : um estudo de caso envolvendo TI e redesenho de negócios. In: XXI ENCONTRO ANUAL DA ANPAD (1997 : Angra dos Reis). Anais Eletrônicos... Rio de Janeiro : ANPAD, 1997.

CAMPOS, D. F. et al.

Desenvolvimento de um sistema de informações como suporte a um programa de manutenção. In: XX ENCONTRO ANUẢL DA ANPAD (1996: Angra dos Reis). Anais... Rio de Janeiro : ANPAD, 1996.

CARVALHO, F. A.

Impact of the perceived importance of information type on the perceived importance of information source in export market decision : an empirical study on brazilian exporters. In: XXI ENCONTRO ANUAL DA ANPAD (1997: Angra dos Reis). Anais Eletrônicos... Rio de Janeiro : ANPAD, 1997.

CASTELLANI, M. R. et al.

Redes de comunicação eletrônica (Internet) : aspectos culturais em pesquisa acadêmica. In: XX ENCONTRO ANUAL DA ANPAD (1996 : Angra dos Reis). Anais... Rio de Janeiro : ANPAD, 1996.

CASTRO, A. C. M.;

LEITE, J. C. S. DO P.

Agregando valor aos sistemas de informação para executivos. In: XXI ENCONTRO ANUAL DA ANPAD (1997: Angra dos Reis). Anais Eletrônicos... Rio de Janeiro : ANPAD, 1997

CÍRIA, F. B.

O uso comercial da Internet por micro, pequenas e médias empresas de Porto Alegre - um estudo exploratório.In: XXI ENCONTRO ANUAL DA ANPAD (1997 : Angra dos Reis). Anais Eletrônicos... Rio de Janeiro : ANPAD, 1997.

CORREA, H. P.; HOPPEN, N.

Seleção de um sistema de telecomunicações utilizando Delphi e AHP. In: XVI ENCONTRO ANUAL DA ANPAD (1992: Canela). Anais... Porto Alegre : ANPAD, 1992. 
CUNHA, M. A.

Administração dos recursos de informática pública : estudo de caso do modelo paranaense. Revista Brasileira de Administração Contemporânea, v. 1, n. 4, 1995.

CUNHA, M. A. et al.

Informática pública estadual : uma análise das preocupações estratégicas dos executivos. In: XX ENCONTRO ANUAL DA ANPAD (1996 : Angra dos Reis). Anais... Rio de Janeiro : ANPAD, 1996.

DE SOUZA, A. A.;

KINGSMAN, B. G.

Modeling the cost-estimation and pricing process in make-to-order companies. In: XX ENCONTRO ANUAL DA ANPAD (1996 : Angra dos Reis). Anais... Rio de Janeiro : ANPAD, 1996.

\section{DETTMER et al.}

Executando regressões utilizando redes neuronais. Revista Brasileira de Administração Contemporânea, v. 1, n. 4, 1995.

DIAS, D. S. et al.

Eficácia de sistemas de informação, participação do usuário e mudança organizacional. In: XVII ENCONTRO ANUAL DA ANPAD (1993: Salvador). Anais... Salvador : ANPAD, 1993.

DIEFENTHAELER, G. et al.

$\mathrm{O}$ uso do método de análise hierárquica em um processo decisório em grupo. In: XV ENCONTRO ANUAL DA ANPAD (1991 : Belo Horizonte). Anais... Belo Horizonte : ANPAD, 1991.

DIEFENTHAELER, R.

O desenvolvimento e a utilização de sistemas baseados em conhecimento segundo o paradigma de apoio. In: XVI ENCONTRO ANUAL DA ANPAD (1992 : Canela). Anais... Porto Alegre : ANPAD, 1992.

DINIZ, E. H.

Redes locais e downsizing de sistemas de informação : um estudo em bancos brasileiros. In: XVIII ENCONTRO ANUAL DA ANPAD (1994: Curitiba). Anais... Curitiba: ANPAD, 1994.

DISCHINGER, L. F. F. et al.

Desenvolvimento de um sistema especialista para a consulta em banco de dados de legislação tributária. In: XV ENCONTRO ANUAL DA ANPAD (1991: Belo Horizonte). Anais... Belo Horizonte : ANPAD, 1991.

DORNELAS, J. S.

Comunicação nas organizações : o que muda com as redes de computadores? Um estudo em Pernambuco. Revista Brasileira de Administração Contemporânea, v. 1, n. 4, 1995.

DORNELAS, J. S.;

HOPPEN, N.

Orçamento público participativo: uma aplicação potencial de Sad-g distribuído. In: XXI ENCONTRO ANUAL DA ANPAD (1997 : Angra dos Reis). Anais Eletrônicos... Rio de Janeiro : ANPAD, 1997.

DORNELLES JR., J.;

HOPPEN, N.

Planejamento de longo prazo de sistemas de informação. In: XV ENCONTRO ANUAL DA ANPAD (1991 : Belo Horizonte). Anais... Belo Horizonte : ANPAD, 1991. 
EHRLICH, P. J.

Modelos quantitativos de apoio às decisões I. Revista de Administração de Empresas, v. 36, n. 1, 1996.

Modelos quantitativos de apoio às decisões II. Revista de Administração de Empresas, v. 36, n. 2, 1996.

ENSSLIN, L. et al.

O uso estratégico da tecnologia da informação. In: XX ENCONTRO ANUAL DA ANPAD (1996: Angra dos Reis). Anais... Rio de Janeiro : ANPAD, 1996.

EVARISTO, A.;

BORENSTEIN, D.

Avaliação de sistemas de informações gerenciais. In: XIV ENCONTRO ANUAL DA ANPAD (1990 : Florianópolis). Anais... Florianópolis : ANPAD, 1990.

FACCHINI, A. R. et al.

Definição de indicadores para avaliação de eficiência e eficácia do uso do correio eletrônico. In: XVII ENCONTRO ANUAL DA ANPAD (1993 : Salvador). Anais... Salvador : ANPAD, 1993.

FEHLABER, A.

A utilização da informática nas empresas distribuidoras de bebidas no estado de Pernambuco. In: XVI ENCONTRO ANUAL DA ANPAD (1992: Canela). Anais... Porto Alegre : ANPAD, 1992.

FEHLABER, A.;

VIEIRA, $M$.

Impactos de informatização nas relações de trabalho : o caso de Pernambuco. In: XVIII ENCONTRO ANUAL DA ANPAD
(1994 : Curitiba). Anais... Curitiba : ANPAD, 1994.

FLECK. D. L.

Exame da evolução da relação entre o órgão de informática e órgãos usuários. In: XV ENCONTRO ANUAL DA ANPAD (1991 : Belo Horizonte). Anais... Belo Horizonte : ANPAD, 1991.

FREITAS, H. M. R. et al.

$\mathrm{O}$ apoio à decisão do usuário final de um sistema de informações em marketing : onde e como intervir ? In: XVI ENCONTRO ANUAL DA ANPAD (1992: Canela). Anais... Porto Alegre : ANPAD, 1992.

Avaliação de sistemas de informações. Revista de Administração, v. 29, n. 4, 1994.

Verificação do impacto de um SAD na redução das dificuldades do decisor. Revista Brasileira de Administração Contemporânea, v. 1, n. 4, 1995.

$\mathrm{Na}$ busca de um método quantiqualitativo para estudar a percepção do tomador de decisão. In: XX ENCONTRO ANUAL DA ANPAD (1996: Angra dos Reis). Anais... Rio de Janeiro : ANPAD, 1996.

Aplicação de sistema de software para auxílio na análise de conteúdo. Revista de Administração, v. 32, n. 3, 1997.

FREITAS, H. M. R.;

BALLAZ, B.

An end-user behaviour typology through an automated assessment method. In: XVII ENCONTRO ANUAL DA ANPAD (1993: Salvador). Anais... Salvador : ANPAD, 1993. 
FREITAS, H. M. R.;

BECKER, J. L.

Uma agenda de pesquisas para a colaboração universidade-empresa em sistemas de informação e de decisão. Revista de Administração, v. 30, n. 2, 1995.

FREITAS, H. M. R.;

KLADIS, C. M.

$\mathrm{Da}$ informação à política informacional das organizações : um quadro conceitual. Revista de Administração Pública, v. 29, n. 3, 1995.

FREITAS, H. M. R.;

LESCA, $\mathrm{H}$.

Competitividade empresarial na era da informação. Revista de Administração, v. 27, n. 3, 1992.

FREIRE, A. R. et al.

Uso estratégico da tecnologia da informação : um estudo exploratório no setor de indústria de mineração e exploração de petróleo do Brasil. In: XVIII ENCONTRO ANUAL DA ANPAD (1994 : Curitiba). Anais... Curitiba : ANPAD, 1994.

\section{FURIATI, N. M. A.}

Um modelo para concepção de sistemas de informações estratégicas. In: XIV ENCONTRO ANUAL DA ANPAD (1990 : Florianópolis).

Anais... Florianópolis : ANPAD, 1990.

GARCIA, J. M. P. L.;

NOGUEIRA, A. R. R.

Administração de dados : um estudo exploratório. In: XIV ENCONTRO ANUAL DA ANPAD (1990 : Florianópolis). Anais... Florianópolis : ANPAD, 1990.
GONÇALVES JR., G.;

LEITÃO, S. P.

Percepção, informação e decisão organizacional. In: XX ENCONTRO ANUAL DA ANPAD (1996 : Angra dos Reis). Anais... Rio de Janeiro : ANPAD, 1996.

GONÇALVES, M. A. et al.

Os papéis do gerente e a qualidade da informação gerencial. Revista Brasileira de Administração Contemporânea, v. 1, n. 4, 1995.

GONÇALVES, C. A.

Tecnologia da informação e marketing : como obter clientes e mercados. Revista de Administração de Empresas, v. 35, n. 4, 1995.

GONÇALVES, C. A. et al.

Marketing de relacionamento e tecnologias de informação : análise em instituições bancárias. In: XXI ENCONTRO ANUAL DA ANPAD (1997: Angra dos Reis). Anais Eletrônicos... Rio de Janeiro : ANPAD, 1997.

GRAHL, E.;

MERLO, R. B.

Um protótipo de gerador de sistemas de apoio à decisão. In: XVII ENCONTRO ANUAL DA ANPAD (1993 : Salvador). Anais... Salvador : ANPAD, 1993.

GRAEML, A. R.

Avaliação comparativa dos programas de informatização de cinco indústrias na Cidade Industrial de Curitiba. In: XXI ENCONTRO ANUAL DA ANPAD (1997 : Angra dos Reis). Anais Eletrônicos... Rio de Janeiro : ANPAD, 1997. 
HOPPEN, N. et al.

O uso do correio eletrônico como suporte ao trabalho cooperativo : uma experiência real. In: XVI ENCONTRO ANUAL DA ANPAD (1992 : Canela). Anais... Porto Alegre : ANPAD, 1992.

Brainstorming eletrônico, anonimato e estímulo de idéias criativas : um estudo de grupos ad hoc e estabelecidos. In: XVIII ENCONTRO ANUAL DA ANPAD (1994 : Curitiba). Anais... Curitiba : ANPAD, 1994.

Avaliação de artigos de pesquisa em sistemas de informação : proposta de um guia. In: XXI ENCONTRO ANUAL DA ANPAD (1997: Angra dos Reis). Anais Eletrônicos... Rio de Janeiro : ANPAD, 1997.

HOPPEN, N.;

ANTUNES, A.

Sistemas especialistas em empresas brasileiras. In: XV ENCONTRO ANUAL DA ANPAD (1991: Belo Horizonte). Anais... Belo Horizonte : ANPAD, 1991.

\section{HOPPEN, N.;}

TRAHAND, J.

Os sistemas especialistas em gestão no Brasil : um desafio. Revista de Administração de Empresas, v. 30, n. 3, 1990.

IDROGO, A.

$\mathrm{O}$ sistema de informações gerenciais na empresa : um estudo do setor têxtil norteriograndense. In: XIV ENCONTRO ANUAL DA ANPAD (1990 : Florianópolis). Anais... Florianópolis : ANPAD, 1990.

KLERING, L. R.

O clima organizacional de CPDs no RS. In: XIV ENCONTRO ANUAL DA ANPAD (1990 :
Florianópolis). Anais... Florianópolis : ANPAD, 1990.

Informatização das prefeituras do RS : diagnóstico da situação atual. In: XVI ENCONTRO ANUAL DA ANPAD (1992: Canela). Anais... Porto Alegre : ANPAD, 1992.

SPPS : sistema de processamento de pesquisas sócio-econômicas. In: XVII ENCONTRO ANUAL DA ANPAD (1993 : Salvador). Anais... Salvador : ANPAD, 1993.

Relação entre estágios de informatização e padrões de comportamento administrativo. In: XVIII ENCONTRO ANUAL DA ANPAD (1994 : Curitiba). Anais... Curitiba : ANPAD, 1994.

KOCK, N. F. et al.

An action research study of a computer-mediated business process redesign group. In: XX ENCONTRO ANUAL DA ANPAD (1996: Angra dos Reis). Anais... Rio de Janeiro : ANPAD, 1996.

\section{LEITÃO, S. P.}

Capacidade decisória em decisões não-estruturadas : uma proposta. Revista de Administração Pública, v. 27, n. 4, 1993.

Repensando a questão da decisão organizacional e seu paradigma. Revista de Administração Pública, v. 29, n. 2, 1995.

Para uma nova teoria da decisão organizacional. Revista de Administração Pública, v. 31, n. 2, 1997.

LEITE, J. C.

Folio views : um software de hipertexto como recurso de 
informática no apoio à atividade acadêmica. In: XVII ENCONTRO ANUAL DA ANPAD (1993 : Salvador). Anais... Salvador : ANPAD, 1993.

Tecnologia e informação : a visão do empresariado brasileiro. Revista Brasileira de Administração Contemporânea, v. 1, n. 4, 1995.

Terceirização em informática sob a ótica do prestador de serviços. In: XXI ENCONTRO ANUAL DA ANPAD (1997 : Angra dos Reis). Anais Eletrônicos... Rio de Janeiro : ANPAD, 1997.

Terceirização em informática no Brasil. Revista de Administração de Empresas, v. 37, n. 3, 1997.

Terceirização em informática sob a ótica do prestador de serviços. Revista de Administracão de Empresas, v. 37, n. 4, 1997.

LESCA, $\mathrm{H}$.

Veille strategique pour le management stratégique : état de la question et axes de recherche. In: XX ENCONTRO ANUAL DA ANPAD (1996 : Angra dos Reis). Anais... Rio de Janeiro : ANPAD, 1996.

LOPES, A. B.

Sistemas de reuniões eletrônicas e apoio à decisão de grupo. In: XVII ENCONTRO ANUAL DA ANPAD (1993 : Salvador). Anais... Salvador : ANPAD, 1993.

LOPES, A. B. et al.

Distribuindo informação financeira on line : um estudo empírico. Revista de Administração, v. 31, n. 4, 1996.
Uma análise do setor de distribuicão de informações financeiras on line no Brasil. In: XX ENCONTRO ANUAL DA ANPAD (1996 : Angra dos Reis). Anais... Rio de Janeiro : ANPAD, 1996.

MAÇADA, A. C. G. et al. Sistema de planejamento dos recursos da saúde. In: XVII ENCONTRO ANUAL DA ANPAD (1993 : Salvador). Anais... Salvador : ANPAD, 1993.

MARIANO, S. R. H. Downsizing em tecnologia da informação : o caso Brahma. Revista de Administração, v. 28, n. 4, 1996.

MAZZILI, C. P.

Análise de contribuição da utilização de um sistema interativo de apoio à decisão de grupo à eficácia e à eficiência de um processo de decisão coletivo. In: XVIII ENCONTRO ANUAL DA ANPAD (1994 : Curitiba). Anais... Curitiba : ANPAD, 1994.

MEIRELLES, F. S.

Dimensões da administração da informática : estruturas de referência. In: XIV ENCONTRO ANUAL DA ANPAD (1990 : Florianópolis). Anais... Florianópolis : ANPAD, 1990.

Modelos quantitativos : uma nova abordagem usando planilhas. In: XV ENCONTRO ANUAL DA ANPAD (1991 : Belo Horizonte). Anais... Belo Horizonte : ANPAD, 1991.

Evolução da microinformática : ciclos, cenários e tendências. Revista de Administração de Empresas, v. 34, n. 3, 1994. 
MONTEIRO, A. DE O.

Reflexões sobre a importância econômica da informação para as organizações produtivas. Organizações e Sociedade, v. 3, n. 6 , 1996.

\section{MORGADO, E. M.}

Avaliação do mercado brasileiro de comunicação de dados - oportunidades estragégicas. In: XVII ENCONTRO ANUAL DA ANPAD (1993 : Salvador). Anais... Salvador : ANPAD, 1993.

MORGADO, E. M. et al.

Avaliando o gerenciamento da tecnologia de informação no setor bancário brasileiro. Revista Brasileira de Administração Contemporânea, v. 1, n. 4, 1995.

\section{MOSCA, N. et al.}

Perfil do uso da informática e estágio de informatização nas empresas indústriais de Natal. In: XXI ENCONTRO ANUAL DA ANPAD (1997 : Angra dos Reis). Anais Eletrônicos... Rio de Janeiro : ANPAD, 1997.

\section{NOGUEIRA, A. R. R.}

Os processos de downsizing e terceirização na utilização estratégica da tecnologia de informação : um estudo exploratório em bancos múltiplos. Revista Brasileira de Administração Contemporânea, v. 1, n. 4, 1995.

Terceirização de serviços de tecnologia de informação : um estudo em bancos comerciais privados. In: XX ENCONTRO ANUAL DA ANPAD (1996 : Angra dos Reis). Anais... Rio de Janeiro : ANPAD, 1996.

NOGUEIRA, A. R. R. et al.

$O$ processo de planejamento para a utilização estratégica da tecnologia de informação : um estudo exploratório. In: XVI ENCONTRO ANUAL DA ANPAD (1992 : Canela). Anais... Porto Alegre: ANPAD, 1992.

Utilização estratégica da tecnologia de informação - um estudo em empresas financeiras do Rio de Janeiro e de São Paulo. In: XVII ENCONTRO ANUAL DA ANPAD (1993 : Salvador). Anais... Salvador : ANPAD, 1993.

Utilização estratégica da tecnologia de informação - um estudo em empresas comerciais do Rio de Janeiro e de São Paulo. In: XVIII ENCONTRO ANUAL DA ANPAD (1994 : Curitiba). Anais... Curitiba : ANPAD, 1994.

$\mathrm{O}$ alinhamento estratégico e a construção do futuro : um estudo exploratório. In: XXI ENCONTRO ANUAL DA ANPAD (1997 : Angra dos Reis). Anais Eletrônicos... Rio de Janeiro : ANPAD, 1997.

OLIVEIRA, L. H.

Potencial e aplicações de sistemas de apoio à decisão para empresas rurais. Revista Brasileira de Administração Contemporânea, $v$. 1, n. 4, 1995.

SIG para a gestão de custos por qualidade : estudo de caso em uma cooperativa de café. In: XXI ENCONTRO ANUAL DA ANPAD (1997 : Angra dos Reis). Anais Eletrônicos... Rio de Janeiro : ANPAD, 1997.

PEDROSO, M. C.

Sistemas de programação da produção com capacidade finita : uma decisão estratégica? Revista de Administração de Empresas, v. 36, n. 4, 1996. 
PEREIRA, A. B. M. et al.

Planejamento de sistemas de informações em um ambiente de mudança tecnológica. In: XX ENCONTRO ANUAL DA ANPAD (1996: Angra dos Reis). Anais... Rio de Janeiro : ANPAD, 1996.

PEREIRA, D.

O trabalho informático como catalisador de inovações técnicoorganizacionais. In: XVII ENCONTRO ANUAL DA ANPAD (1993 : Salvador). Anais... Salvador : ANPAD, 1993.

PITANGUEIRA, R. S. et al.

Um estudo sobre a implantação da computação distribuída. In: XVIII ENCONTRO ANUAL DA ANPAD (1994 : Curitiba). Anais... Curitiba : ANPAD, 1994.

POZZEBON, M. et al.

Construindo um EIS (enterprise information system) da (e para a) empresa. Revista de Administração, v. 31, n. 4, 1996.

Características desejáveis de um EIS - enterprise information system - rumo à proatividade. In: XXI ENCONTRO ANUAL DA ANPAD (1997 : Angra dos Reis). Anais Eletrônicos... Rio de Janeiro : ANPAD, 1997.

Pela aplicabilidade - com um maior rigor científico - dos estudos de caso em sistemas de informação. In: XXI ENCONTRO ANUAL DA ANPAD (1997 : Angra dos Reis). Anais Eletrônicos... Rio de Janeiro : ANPAD, 1997.

PROTIL, R. M.

Simulação computacional como método universal de otimização do processo decisório na administração. Revista Brasileira de Administração Contemporânea, $v$. 1, n. 4, 1995.
REINHARD, N.

Evolução das ênfases gerenciais e de pesquisa na área de tecnologia de informática e de comunicaçôes aplicada nas empresas. Revista de Administração, v. 31 , n. 4, 1996.

RICCIO, E. L. et al.

Controladoria e benchmarking : aplicação em uma empresa de classe mundial. Revista Brasileira de Administração Contemporânea, v. 1, n. 4, 1995.

RODRIGUES, F. J. et al.

$O$ paradigma interpretativo na pesquisa e desenvolvimento de sistemas de informação. 1998. (mimeo).

ROSA, S. I. V. et al.

SECOX-HI : aplicação de um modelo híbrido para sistemas especialistas em um problema decisório complexo. Revista Brasileira de Administração Contemporânea, v. 1, n. 4, 1995.

SANCHES, O. M.

Estratégias para a implantação e gerência de sistemas de informação de apoio à tomada de decisões. Revista de Administração Pública, v. 31, n. 4, 1997.

SANCHES, R. et al.

A influência da administração do processo de construção do software na manutenção. In: XX ENCONTRO ANUAL DA ANPAD (1996 : Angra dos Reis). Anais... Rio de Janeiro : ANPAD, 1996.

SANTOS, A. P. L. et al.

Requisitos para projetos de ambientes de sistemas especialistas. In: XIV ENCONTRO ANUAL DA ANPAD (1990: Florianópolis). Anais... Florianópolis : ANPAD, 1990. 
SCHULER, M. et al.

Uma ajuda possante na implantação de sistema de informações para o planejamento estratégico das empresas. In: XVIII ENCONTRO ANUAL DA ANPAD (1994 : Curitiba). Anais... Curitiba : ANPAD, 1994.

SILVA, J. A. R.;

OLIVEIRA, C.V.

O marketing na internet.BR - uma avaliação da presença empresarial na world wide web. In: XXI ENCONTRO ANUAL DA ANPAD (1997: Angra dos Reis). Anais Eletrônicos... Rio de Janeiro : ANPAD, 1997.

SILVA, N. C. et al.

Sistema informatizado de controle de infecção hospitalar. Revista de Administração, v. 26, n. 4, 1991.

SILVEIRA JR., A.

A informática na administração pública federal. In: XVII ENCONTRO ANUAL DA ANPAD (1993 : Salvador). Anais... Salvador: ANPAD, 1993.

SILVEIRA JR., A. et al.

Administração da informação : uma análise de citação. In: XX ENCONTRO ANUAL DA ANPAD (1996: Angra dos Reis). Anais... Rio de Janeiro : ANPAD, 1996.

SOARES, R. O.;

HOPPEN, N.

Aspectos da utilização da internet pelos bancos no Brasil : um estudo baseado em home pages. Organizações e Sociedade, v. 4, n. $8,1997$.

SOUZA, A. A. et al.

CEPSS - a decision support tool for cost estimation and pricing in make-to-order companies. In: XXI ENCONTRO ANUAL DA ANPAD (1997: Angra dos Reis). Anais Eletrônicos... Rio de Janeiro : ANPAD, 1997.

STENZEL, M. G. et al.

Intensidade de informação nos produtos e processos das empresas industriais manufatureiras e de processo e o uso estratégico da tecnologia de informação. In: XV ENCONTRO ANUAL DA ANPAD (1991 : Belo Horizonte). Anais... Belo Horizonte : ANPAD, 1991.

STUMPF, M. K. et al.

A gestão da informação em um hospital universitário : em busca do "patient core record" do Hospital de Clínicas de Porto Alegre. In: XX ENCONTRO ANUAL DA ANPAD (1996 : Angra dos Reis). Anais... Rio de Janeiro : ANPAD, 1996.

TAKAHASHI, S. et al.

An intregrated environment for information management in the new products development process. Revista Brasileira de Administração Contemporânea, v. 1, n. 4, 1995.

TELMA, R. R.

$\mathrm{O}$ uso de modelos de simulação dinâmica na administração estratégica. In: XVI ENCONTRO ANUAL DA ANPAD (1992: Canela). Anais... Porto Alegre : ANPAD, 1992.

TIETELROIT, R. et al.

Metodologia JAD - joint application design : um novo enfoque de modelagem de sistemas? In: XV ENCONTRO ANUAL DA ANPAD (1991: Belo Horizonte). Anais... Belo Horizonte : ANPAD, 1991. 
TORRES, N. O.

Processo de modernização da informática na EAESP-FGV e a entrada em CBT - computer based training. In: XVII ENCONTRO ANUAL DA ANPAD (1993 : Salvador). Anais... Salvador : ANPAD, 1993.

TRISTÃO, G.

Informatização : um problema de treinamento ou de mudança da cultura. In: XV ENCONTRO ANUAL DA ANPAD (1991 : Belo Horizonte). Anais... Belo Horizonte : ANPAD, 1991.

\section{VARGAS, L.}

Determinantes culturais da aceitação das aplicações informáticas do usuário final. In: XV ENCONTRO ANUAL DA ANPAD (1991 : Belo Horizonte). Anais... Belo Horizonte : ANPAD, 1991.

VEIGA, R. T.

Mensuração de aspectos qualitativos da demanda de software. In: XVIII ENCONTRO ANUAL DA
ANPAD (1994: Curitiba). Anais... Curitiba : ANPAD, 1994.

VEIGA R. T. et al.

Construção de escalas likert com o auxílio de planilha eletrônica. In: XVII ENCONTRO ANUAL DA ANPAD (1993 : Salvador). Anais... Salvador : ANPAD, 1993.

VERGARA, S. C.

Sobre a intuição na tomada de decisão. Revista de Administração Pública, v. 27, n. 2, 1993.

ZWICKER, R. et al.

Aprendizagem e uso de sistemas de informações : aquisição de habilidades cognitivas através de treinamento inteligente auxiliado pelo computador. In: XVII ENCONTRO ANUAL DA ANPAD (1993 : Salvador). Anais... Salvador: ANPAD, 1993.

Sistemas especialistas : um hiato de aplicabilidade. Revista de Administração, v. 28, n. 4, 1993. 